\title{
Cold Working Process on Hard Metal Stacked Assembly
}

\author{
Guillaume Pichon ${ }^{1(凶)}$, Alain Daidie ${ }^{1}$, Adeline Fau $^{1}$, Clément Chirol$^{2}$, \\ and Audrey Benaben ${ }^{2}$ \\ ${ }^{1}$ Université de Toulouse, Institut Clément Ader, UMR CNRS 5312, INSA/UPS/ISAE/Mines \\ Albi, Toulouse, France \\ guillaume.pichondairbus.com \\ 2 Airbus Operations S.A.S., Toulouse, France
}

\begin{abstract}
Designed for aeronautical and automotive applications, the split sleeve cold expansion process is used to improve the fatigue life of bolted metallic parts. Although its application has been well tested on aluminum assemblies, hard metal applications are still being studied. This paper presents experimental results of double bolt joint assemblies under double shear fatigue tests after stacked split sleeve cold expansion. The behaviors of two sizes of assemblies with different degrees of expansion are investigated. S-N curves are the main indicators of this study but thermal aspects are also investigated to observe fretting in the specimens as bolts are preloaded. Bolt tension is a major parameter in assembly regarding fatigue life. Interference between those two phenomena is at the heart of this paper. The first results show that stacked cold expansion has a negative effect on mechanical performances, as it deteriorates the fatigue life of the assembly. However, an examination of these results provides a coherent explanation for the loss of performance that occurs.
\end{abstract}

Keywords: Cold expansion $\cdot$ Process $\cdot$ Fatigue $\cdot$ Assembly $\cdot$ Bolt

\section{Introduction}

Reducing the weight of structures is one of the major aims of aeronautical engineers, and specifically concerns structural parts made of hard, heavy metal. Furthermore, modern concern regarding environmental issues has strengthened the will of aircraft manufacturers to focus their innovation efforts on weight loss in order to reduce fuel consumption. For instance, the Dutch aviation industry has planned to cut its global $\mathrm{CO}_{2}$ emissions by one-third by the year 2030 [1]. Some studies focus on new materials such as composites, which have created a breakthrough in the field of aeronautical structures [2]. Nevertheless, their complexity and characteristics (mechanical and thermal) make them unusable for some structural parts so far. Hard metals, and titanium alloys in particular, remain the best solutions in certain cases and are thus frequently used [3]. However, developing new and more efficient technology on ancient material is also a field of study that remains a technical challenge. Aeronautical structures are mainly made of sub-assemblies held 
together by a significant number of fasteners (rivets or bolts). The cold expansion process is an innovative way to enhance the fatigue life of metal components by reinforcing the hole edges to delay their failure. It is then possible to reduce the design weight and achieve identical mechanical performances, while saving weight on the total structure. Several cold expansion process exist: expansion by conical pin, the British railways process, and a conical four-split mandrel. This paper focus on the split sleeve expansion process.

\section{Stacked Cold Expansion Process}

The Cold Expansion patented by Fatigue Technologies Inc. [4, 5] is the most widely used, mainly because of its speed of execution and portability [6]. By pulling an oversized mandrel through a fastener hole, compressive residual stresses are developed around the hole wall, fatigue crack propagation is delayed and maintenance sessions can be scheduled less frequently [7]. The process is performed with the help of a split sleeve, placed longitudinally between the mandrel and the hole. A conical taper mandrel is screwed at the extremity of a pressure cylinder. To guide the mandrel and to maintain the sleeve in position during expansion, a nosecap, symmetrically split into four sections, is inserted around the mandrel and directly mounted onto the puller unit frame. Then, the split sleeve is placed around the mandrel, and the mandrel and sleeve assembly is inserted inside the specimen hole. Finally, as the mandrel travels through the material, the hole is expanded at a ratio defined by the Degree of Cold Expansion (DCE) expressed by Eq. (1)

$$
D C E=\frac{d_{0}^{m}+2 t^{s s}-d_{0}^{s p}}{d_{0}^{s p}} \times 100
$$

where $\mathrm{d}_{0} \mathrm{~m}$ is the mandrel major diameter, $\mathrm{t}^{\mathrm{ss}}$ is the split sleeve thickness and $\mathrm{d}_{0}{ }^{\mathrm{sp}}$ is the initial hole diameter.

In this particular study, the mandrel is extracted by travelling through the 3 plates, which are clamped together. Once the first hole expansion is achieved, a temporary bolt is inserted around the sleeve, which is left in the hole to preserve correct alignment. Then the second hole is expanded with the same clamping system. The process is presented schematically in Fig. 1.

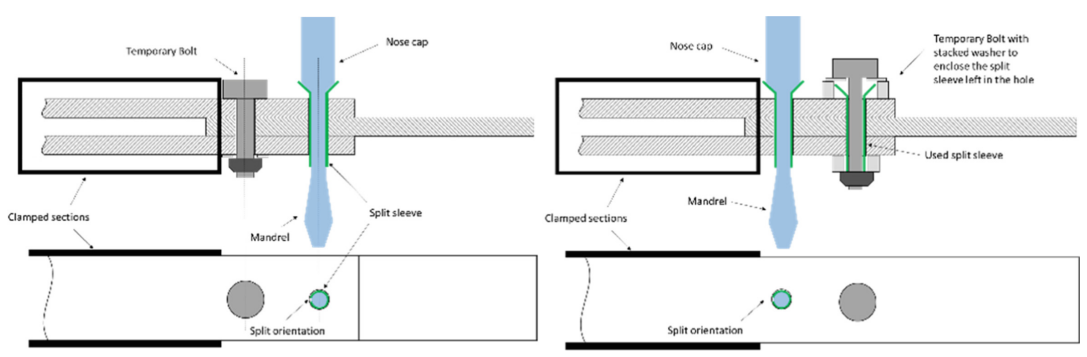

Fig. 1. Stacked cold working process 
During the classic process, plates are expanded individually and the local deformations of the metal plates create a volcano on each face of the coupon. In his works, [8] performed cold working expansion on several similar coupons and the measured heights of such volcanoes were around a tenth of a millimeter. Although the coupons are stacked and strongly clamped in the present work, similar deformations are present, as shown by Fig. 2.

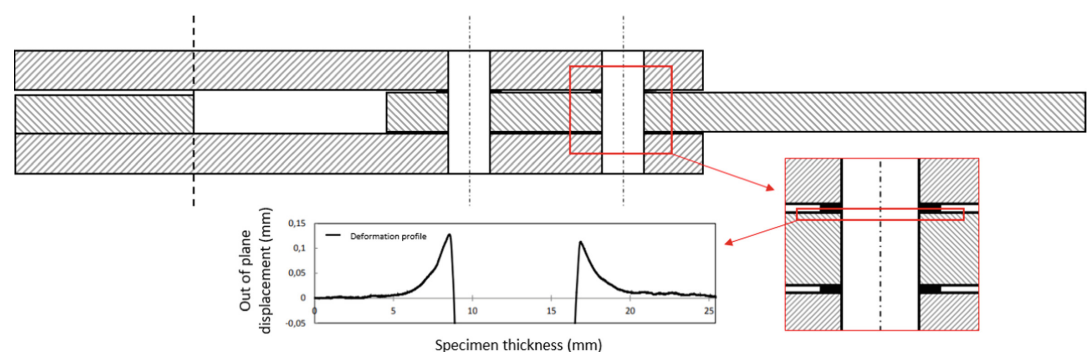

Fig. 2. Volcano formation at hole edge

\section{Experimental Campaign}

Assemblies in this study were made of titanium Ti-6Al-4V. Dimensions are given in Table 1, in accordance with the design in Fig. 3. Two different sizes of fasteners were tested, code-4 (6.35 mm diameter) and code-6 (9.352 mm diameter). Non-expanded assemblies were also tested for each code as references. Hard metals are usually strongly loaded so it was interesting to study their behavior at high cold expansion rate. Therefore the chosen DCE (degree of cold expansion) was $5 \%$ for each size. The coupons were designed to favor a net section failure at the first bolt of the middle part (Fig. 3).

The last step before the test was final assembly with the dedicated fasteners. In this study, the bolts used were shear screws with self-locking nuts. Since T. Benhaddou [9, 10] has demonstrated the major impact that preload has on the fatigue life of bolted assemblies, it was decided to use a high tightening torque to compensate the clearance between plates caused by the stacked expansion. The tightening torque Co was 29 N.m for code- 6 assemblies and $9.5 \mathrm{~N} . \mathrm{m}$ for code- 4 . This tightening was executed with a numerical torque wrench having a precision range of $4 \%$. However, strong uncertainty remained between the torque applied and the existing preload in the fasteners due to the numerous parameters involved in the process, such as torqueing speed, temperature, friction coefficients.

The fatigue tests were conducted with a frequency of $5 \mathrm{~Hz}$ and a load factor $\mathrm{R}=0.1$ (see Eq. 2).

$$
R=\frac{\sigma_{\min }}{\sigma_{\max }}=0.1
$$

The stress levels were chosen in order to obtain points ranging from $10^{3}$ to $2.10^{6}$ cycles. To take proper account of the dispersion effect inherent in fatigue tests, three assemblies were tested for each configuration (size and DCE). 
Table 1. Specimen designations and dimensions

\begin{tabular}{|c|c|c|c|c|c|c|c|c|c|c|}
\hline \multirow[t]{3}{*}{ Reference } & \multicolumn{4}{|c|}{ Designation } & \multicolumn{6}{|c|}{ Dimensions } \\
\hline & Code & $\mathrm{T}$ & TTH & DCE & Ltot & Ttot & $\mathrm{W}$ & $\mathrm{Di}$ & Dr & $S$ \\
\hline & {$[-]$} & {$[\mathrm{mm}]$} & {$[\mathrm{NA}]$} & {$[\%]$} & {$[\mathrm{mm}]$} & {$[\mathrm{mm}]$} & {$[\mathrm{mm}]$} & {$[\mathrm{mm}]$} & {$[\mathrm{mm}]$} & {$\left[\mathrm{mm}^{2}\right]$} \\
\hline 4-3-0-0 & 4 & \multirow[t]{2}{*}{3.18} & \multirow[t]{4}{*}{0} & 0 & \multirow[t]{2}{*}{254} & \multirow[t]{2}{*}{9.525} & \multirow[t]{2}{*}{25.4} & $6.35 \pm 0.02$ & \multirow[t]{2}{*}{6.35} & \multirow[t]{2}{*}{60.48} \\
\hline $4-3-0-5$ & 4 & & & 5 & & & & $5.93 \pm 0.02$ & & \\
\hline 6-4-0-0 & 6 & \multirow[t]{2}{*}{4.76} & & 0 & \multirow[t]{2}{*}{381} & \multirow[t]{2}{*}{14.287} & \multirow[t]{2}{*}{38.1} & $9.52 \pm 0.02$ & \multirow[t]{2}{*}{9.525} & \multirow[t]{2}{*}{136.09} \\
\hline $6-4-0-5$ & 6 & & & 5 & & & & $8.89 \pm 0.02$ & & \\
\hline
\end{tabular}

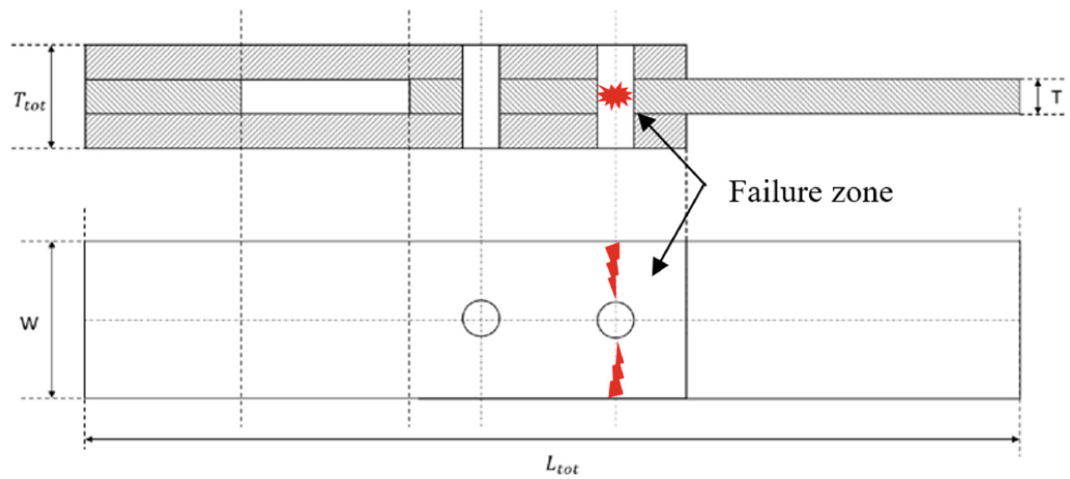

Fig. 3. Definition of assemblies

Specific metrology devices were installed to observe fretting behavior during the tests.

\section{Results}

The direct outputs of this experimental phase were the S-N curves or Whöler curves presented in Fig. 4. A glance at the curves shows that the fatigue lives of the expanded assemblies (green) were lower than the references (blue and red).

a)

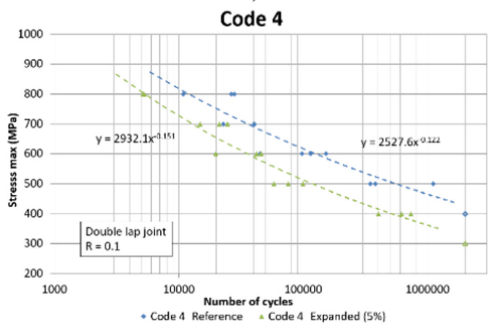

b)

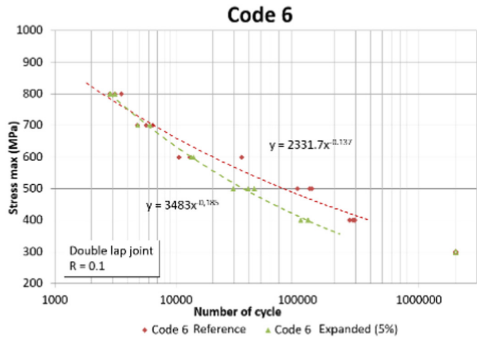

Fig. 4. S-N curves a) Code-4, b) Code-6 
To explain such a difference, the failures of the assemblies were analyzed. For expanded assemblies, $100 \%$ of failures occurred in the net section as expected whereas, for the reference ones, only $95 \%$ of failures were located in the net section. The others were tangent to the hole. This failure mode can be explained by the strong preload of the fasteners.

Figure 5 shows the fretting zone of the assemblies tested and compares expanded and reference coupons for similar loading. On expanded assemblies, the fretting is concentrated around the holes, while the fretting zones on reference coupons are larger and scattered all over the contact surface. From these observations, it can be deduced that the load transmitted by friction was significantly lower on expanded assemblies, so the load was mainly transmitted by the fasteners and the holes. This behavior is consistent with the performance loss, assessed at about $15 \%$ (for $10^{5}$ cycles).

a)

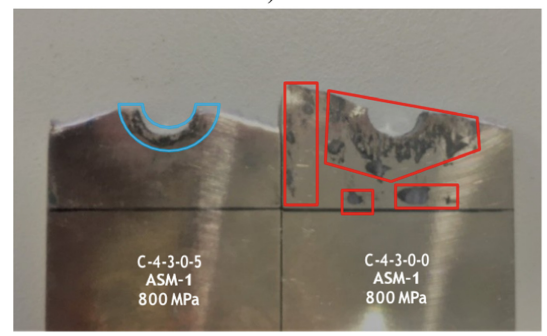

b)

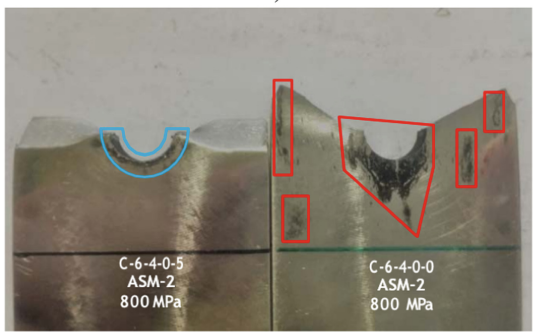

Fig. 5. Fretting zones of expanded (blue) and reference (red) assemblies, a) Code- 4 , b) Code- 6

The thermal evolution of the assemblies (reference and expanded, code- 6 , at $500 \mathrm{MPa}$ loading) is presented in Fig. 6. The reference assembly reaches a much higher temperature than the expanded one during the first phase. More friction occurs in the reference assembly, which is coherent with the previous analysis. Then fretting occurs and the heat created by friction decreases as more and more fretting occurs (appearance of black powder). The last peak of the curves shows the heat created during the plasticization of the material. Once again, it can be seen that the reference peak is much higher than that of the expanded assembly. Plastic deformation is less pronounced on expanded assemblies as the cold working process reduces their plasticizing range. 


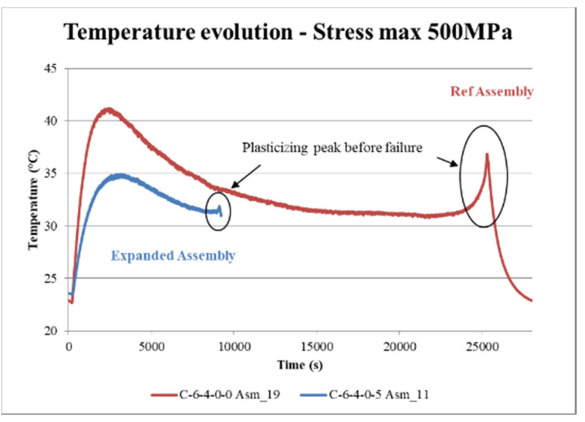

Fig. 6. Thermal evolution of the assemblies during the fatigue test (Code-6)

\section{Conclusion and Perspectives}

Although this study has shown that the stacked cold expansion process combined with strong tightening of bolts has a strong detrimental impact on the fatigue life of hard alloy assemblies, cold expansion alone is not to blame for such a performance decrease.

Deeper investigations should be conducted to determine the impact of cold working on titanium bolted joints, with the implementation of different parameters and configurations. In the near future, experimental tests should be carried out with interface sealant to modify the fretting behavior, while others should be performed with hand tightened bolts to remove the effects of bolt preload.

Simulations are also being developed to study the stacked cold expansion phenomenon, in particular the formation of volcanoes, which are at the origin of gaps between plates and the limited surface friction.

A scale effect was also observed in both reference cases, and expanded assemblies showed a longer life in code 4 than in code 6 . This scale effect is to be confirmed by other tests with larger dimensions.

Acknowledgments. The research work reported here was made possible by Airbus Operations.

\section{References}

1. Luchtvaart Nederland. Slim én duurzaam. Action plan. Ministry of Infrastructure, Amstelveen, The Netherlands (2018)

2. Huggins, G.L., West, R.R., Briscoe, R.T., Welch, J.M.: Engine pylon made from composite material (2012)

3. Boyer, R.: An overview on the use of titanium in the aerospace industry. Mater. Sci. Eng. A 213, 103-114 (1996)

4. FTI. Cold expansion of holes using the standard split sleeve system and countersink cold expansion. Process Specification 8101C. Fatigue Technology Inc. Seattle, WA (2014)

5. Quincey, D.E., Copple, C.M., Walsh, W.B., Jarzebowicz, R.Z., Easterbrook, E.T.: Split sleeve cold expansion (1994) 
6. McCLUNG, R.C.: A literature survey on the stability and significance of residual stresses during fatigue. Fatigue Fract. Eng. Mater. Struct. 30, 173-205 (2007). https://doi.org/10.1111/ j.1460-2695.2007.01102.x

7. Leon, A.: Benefits of split mandrel coldworking. Int. J. Fatigue 20, 1-8 (1998). https://doi. org/10.1016/S0142-1123(97)00059-5

8. Achard, V., Daidié, A., Paredes, M., Chirol, C.: Optimization of the cold expansion process for titanium holes. Adv. Eng. Mater. 19 (2016). https://doi.org/10.1002/adem.201500626

9. Benhaddou, T., Stephan, P., Daidié, A., Chirol, C., Tuery, J.-B.: Effect of axial preload on double-lap bolted joints: numerical study, nantes. In: Proceedings of ASME 2012, 11th Biennial Conference on Engineering Systems Design and Analysis (2012)

10. Benhaddou, T., Daidié, A., Stephan, P., Chirol, C., Tuery. J.-B.: Optimization of fatigue behavior of metallic shear joints. In: Proceedings of 12th International Conference on the Mechanical Behavior of Materials - ICM12. Karlsruhe, Germany (2015)

Open Access This chapter is licensed under the terms of the Creative Commons Attribution 4.0 International License (http://creativecommons.org/licenses/by/4.0/), which permits use, sharing, adaptation, distribution and reproduction in any medium or format, as long as you give appropriate credit to the original author(s) and the source, provide a link to the Creative Commons license and indicate if changes were made.

The images or other third party material in this chapter are included in the chapter's Creative Commons license, unless indicated otherwise in a credit line to the material. If material is not included in the chapter's Creative Commons license and your intended use is not permitted by statutory regulation or exceeds the permitted use, you will need to obtain permission directly from the copyright holder.

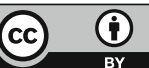

